ROVARIS, E. et al. Efeito do ninho com coleta manual versus automática na eclosão de ovos incubáveis. PUBVET, Londrina, V. 8, N. 18, Ed. 267, Art. 1779, 2014.

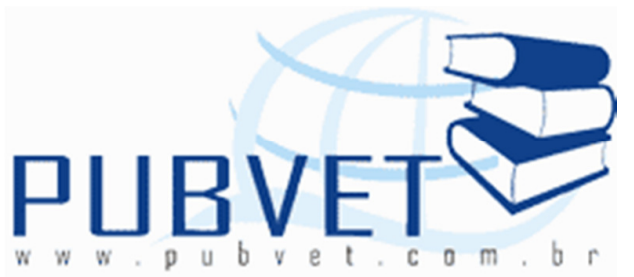

PUBVET, Publicações em Medicina Veterinária e Zootecnia.

\title{
Efeito do ninho com coleta manual versus automática na eclosão de ovos incubáveis
}

\begin{abstract}
Ellen Rovaris ${ }^{1}$, Gerusa da Silva Salles Corrêa ${ }^{2}$, André Brito Corrêa ${ }^{2}$, João Garcia Caramori J unior ${ }^{2}$, Uanderson Verrissímo de Luna ${ }^{1}$, Saullo Diogo de Assis ${ }^{1}$
\end{abstract}

${ }^{1}$ Mestrandos do programa de pós-graduação em Ciência Animal, Universidade Federal de mato grosso, UFMT, Cuiabá, MT. E-mail: ellenrovaris@hotmail.com. ${ }^{2}$ Profs. Drs. Adjuntos Dept $^{\circ}$ de Ciências Básicas e Produção Animal, FAMEV/ UFMT, Cuiabá, MT.

\section{Resumo}

Com o objetivo de avaliar a qualidade de ovos férteis e o nascimento de pintinhos em dois diferentes sistemas de coleta de ovos, manual e automático, foi realizado o estudo a partir de dados de campo de uma empresa avícola situada em MT. Foram avaliados 18060 ovos oriundos de matrizes pesadas com idades de 35 a 45 semanas. Foram avaliados no incubatório a eclodibilidade dos ovos, número de ovos trincados e a porcentagem de contaminação por bactérias e fungos. Na granja avaliou-se a porcentagem de ovos postos na cama e a porcentagem de ovos incubáveis. Os resultados mostraram que os ovos coletados em ninhos automáticos apresentaram melhores resultados de eclodibilidade e menores porcentagens de contaminação bacteriana e fúngica. Já os ninhos manuais apresentaram maiores índices de aproveitamento para incubação e menores índices de ovos 
ROVARIS, E. et al. Efeito do ninho com coleta manual versus automática na eclosão de ovos incubáveis. PUBVET, Londrina, V. 8, N. 18, Ed. 267, Art. 1779, 2014.

de cama. Não houve diferença no número de ovos trincados entre ninhos e idades das matrizes.

Palavras-chave: eclodibilidade, matrizes de frango de corte, ovos de cama, tipos de ninho.

\title{
Effect of nest collection with manual versus automatic hatches eggs hatching
}

\begin{abstract}
In order to evaluate the quality of fertile eggs and chicks born in two different systems of collecting eggs, manual and automatic, a study was conducted from field data of a poultry company located in Mato Grosso, Brazil. Was evaluated the hatchery hatchability, cracked eggs and contamination by bacteria and fungi, the farm was evaluated eggs laid on the floor and use. The results showed that eggs collected from automated nests had better results and lower hatchability percentages of bacterial and fungal contamination, on the other hand, the manual nests showed higher recovery for incubation and lower floor eggs, cracked eggs in relation to no difference. There was no difference of the number of cracked eggs between nests and broiler breeders age.
\end{abstract}

Keywords: hatchability, floor eggs, broiler matrices, types of nest.

\section{Introdução}

Um bom nascimento de pintos inicia-se com a coleta de ovos na granja, o qual deve ser coletado, desinfetado e transportado, imediatamente após a postura, para o incubatório (Rosa e Avila, 2000).

De acordo com a Cobb- Vantress (2008) a eclodibilidade máxima e excelente qualidade dos pintos só poderão ser obtidas se os ovos forem mantidos em ótimas condições entre a postura e a incubação. Uma vez posto, seu potencial de eclodibilidade pode, no máximo, ser mantido, mas não 
ROVARIS, E. et al. Efeito do ninho com coleta manual versus automática na eclosão de ovos incubáveis. PUBVET, Londrina, V. 8, N. 18, Ed. 267, Art. 1779, 2014.

melhorado. Se os ovos forem manipulados de forma errada, o potencial de eclodibilidade irá diminuir rapidamente.

Os ninhos automáticos proporcionam uma coleta mais rápida em relação aos ninhos manuais. Como descreve Silva (2012), o ninho automático impede que as aves tenham contato com os ovos após a postura e a permanência dos ovos no local da postura é menor, gerando menor incidência de trincas e contaminação e assim melhor qualidade dos ovos. Além disso, a mão de obra pode ser reduzida em torno de 30 a 40\%. Porém, tem um alto custo inicial e maior propensão para a postura de ovos na cama.

Os ninhos manuais são preferidos pelas aves, conforme trabalhos realizados por Holcmanet al. (2007), que mostraram que as aves preferem ninhos forrados com maravalha ao invés de material plástico.

Em trabalho realizado por Piloto et al. (2010), no qual analisam a qualidade dos ovos, foi observado que os ninhos com coleta manual proporcionaram ovos com melhor qualidade em relação aos ninhos adaptados para coleta automática.

Em função de pouca informação científica e com resultados contraditórios, realizou-se esta pesquisa visando a avaliação dos ovos coletados nos dois sistemas, manual e automático, em relação à eclodibilidade, contaminação bacteriana e fúngica, índices de aproveitamento para incubação e número de ovos de cama.

\section{Material e Métodos}

O experimento foi conduzido em aviários de uma empresa integradora, localizados na região médio norte de Mato Grosso. A empresa aloja matrizes de mesma linhagem comercial. O delineamento utilizado foi o inteiramente casualizado, considerando o esquema fatorial de $2 x 11$, sendo dois tipos de ninhos (manual e automático) x onze idades de matrizes Cobb $(35,36,37,38$, $39,40,41,42,43,44$ e 45 semanas de idade). 
ROVARIS, E. et al. Efeito do ninho com coleta manual versus automática na eclosão de ovos incubáveis. PUBVET, Londrina, V. 8, N. 18, Ed. 267, Art. 1779, 2014.

Realizou-se a avaliação de 18060 ovos em incubatório comercial, estes advindos da mesma granja que possui aviários com capacidade de alojamento de 14000 aves. Os aviários dos matrizeiro são equipados com telha isotérmica, exaustores, pad coling (placas evaporativas) e controladores automáticos dos equipamentos.

Os tratamentos consistiram em dois diferentes tipos de ninhos. Tratamento 1: ninho de coleta manual, de madeira com 8 bocas, forrados com palha de arroz, sendo disponível 1 boca para cada 4 galinhas. As coletas dos ovos do ninho foram realizadas 5 vezes ao dia e a coleta dos ovos da cama 12 vezes ao dia. A palha de arroz era reposta e desinfetada uma vez na semana com paraformol. Tratamento 2: ninho automático, com 1 módulo para cada 220 galinhas, forrados com tapetes plásticos, os tapetes foram limpos antes de iniciar o experimento e as esteiras desinfetadas semanalmente, sendo realizadas duas coletas ao dia, logo pela manhã e no início da tarde e 17 coletas de cama. Foram avaliados 860 ovos em cada nascimento (cada nascimento representa uma repetição). Antes da incubação foram classificados através do uso de uma lanterna em uma sala escura, sendo que os ovos que apresentavam trincas foram retirados das bandejas antes da incubação. Ao nascimento foram avaliados a eclodibilidade e realizada a quebra dos ovos não eclodidos, onde foram determinadas a porcentagem de contaminação por fungo e bactéria (avaliação visual). Ao final de todos os dias de coleta, foram calculados a porcentagem de ovos encontrados na cama e de ovos incubáveis (taxa de aproveitamento). Ovos inférteis não foram considerados.

Os ovos advindos da granja foram armazenados por 4 dias à $20^{\circ} \mathrm{C}$ e umidade de 75 a $85 \%$, posteriormente encaminhados ao pré-aquecimento por 6 horas antes da incubação em sala específica para esta finalidade a uma temperatura de $28^{\circ} \mathrm{C}$ sendo que a temperatura dos ovos foi monitorada por termômetro de raio infravermelho. Após o pré-aquecimento foram colocados na incubadora de múltiplo estágio, a temperatura de $37,3^{\circ} \mathrm{C}$ e umidade de 50 a $60 \%$, a qual foi mantida por bicos pulverizadores, viragem automática de 
ROVARIS, E. et al. Efeito do ninho com coleta manual versus automática na eclosão de ovos incubáveis. PUBVET, Londrina, V. 8, N. 18, Ed. 267, Art. 1779, 2014.

$45^{\circ}$ a cada hora. Aos 19 dias de incubação foram transferidos para o nascedouro a temperatura de $36^{\circ} \mathrm{C}$ e umidade de $87 \%$.

Os dados foram submetidos à análise de variância e para diferença entre médias utilizou-se o teste Student Newman Keuls, ao nível de 5\% de probabilidade. Utilizou-se para a análise o pacote estatístico SAEG (2008).

\section{Resultados e discussão}

As porcentagens de eclodibilidade, contaminação bacteriana, contaminação por fungos e ovos trincados estão apresentados na tabela 1.

Tabela 1. Porcentagem de eclodibilidade, contaminação bacteriana, contaminação por fungos e ovos trincados advindos de dois tipos de ninho, nas diferentes idades das matrizes.

\begin{tabular}{|c|c|c|c|c|c|c|c|c|}
\hline & \multicolumn{2}{|c|}{ Eclodibilidade (\%) } & \multicolumn{2}{|c|}{$\begin{array}{c}\text { Contaminação bacteriana } \\
(\%)\end{array}$} & \multicolumn{2}{|c|}{$\begin{array}{l}\text { Contaminação } \\
\text { fúngica (\%) }\end{array}$} & \multicolumn{2}{|c|}{ Trincados (\%) } \\
\hline \multirow[b]{2}{*}{$\begin{array}{c}\text { Idade } \\
\text { (semanas) }\end{array}$} & \multicolumn{8}{|c|}{ Tratamentos } \\
\hline & Manual & Automático & Manual & Automático & Manual & Automático & Manual & Automático \\
\hline 35 & $88,11 \mathrm{bE}$ & 91,63 aA & $0,25 \mathrm{bBCD}$ & $0 \mathrm{aA}$ & $0 a A$ & $0 \mathrm{aA}$ & $1,630 \mathrm{aA}$ & $0,964 a A$ \\
\hline 36 & $88,75 \mathrm{bDE}$ & 92,09 aA & $0,09 \mathrm{aA}$ & $0 \mathrm{aA}$ & $0 \mathrm{aA}$ & OaA & $1,288 \mathrm{aA}$ & $0,961 \mathrm{aA}$ \\
\hline 37 & $89,56 \mathrm{bCDE}$ & 92,27 aA & $0,10 \mathrm{aA}$ & $0,15 a B$ & $0 a A$ & $0 \mathrm{aA}$ & $2,038 \mathrm{aA}$ & $1,597 \mathrm{aA}$ \\
\hline \multirow[t]{2}{*}{38} & 90,83 & $92,01 \mathrm{aA}$ & $0,19 \mathrm{aBC}$ & $0,39 \mathrm{bc}$ & $0 \mathrm{aA}$ & OaA & $1,436 \mathrm{aA}$ & $2,035 \mathrm{aA}$ \\
\hline & bABCD & & & & & & & \\
\hline 39 & 91,19 аАВC & $91,56 \mathrm{aA}$ & 0,43 bABCDE & $0,39 b \mathrm{~b}$ & $0 \mathrm{aA}$ & OaA & $2,720 \mathrm{aA}$ & $1,123 \mathrm{aA}$ \\
\hline \multirow[t]{2}{*}{40} & 90,39 & $91,85 \mathrm{aA}$ & $0,53 \mathrm{bBCDE}$ & $0 \mathrm{aA}$ & $0 \mathrm{aA}$ & $0 \mathrm{aA}$ & $2,045 a A$ & $2,333 a A$ \\
\hline & bABCDE & & & & & & & \\
\hline \multirow[t]{2}{*}{41} & 89,93 & 91,70 aA & $0,35 \mathrm{bABCDE}$ & $0 \mathrm{aA}$ & $0 a A$ & $0 \mathrm{aA}$ & $1,510 a A$ & $1,711 \mathrm{aA}$ \\
\hline & $\mathrm{bBCDE}$ & & & & & & & \\
\hline 42 & $89,53 \mathrm{bCDE}$ & $91,36 \mathrm{aA}$ & 0,38 bABCDE & $0 \mathrm{aA}$ & $0,04 b B$ & OaA & $1,626 \mathrm{aA}$ & $1,271 \mathrm{aA}$ \\
\hline 43 & $89,46 \mathrm{bCDE}$ & 91,42 aA & 0,44 bABCDE & $0,14 a B$ & $0,06 \mathrm{bC}$ & $0 \mathrm{aA}$ & $2,425 \mathrm{aA}$ & $1,271 \mathrm{aA}$ \\
\hline 44 & $89,21 \mathrm{bCDE}$ & $92,19 \mathrm{aA}$ & $0,36 a A B C D E$ & $0,51 b c$ & $0 \mathrm{aA}$ & $0 \mathrm{aA}$ & $2,111 \mathrm{aA}$ & $1,551 \mathrm{aA}$ \\
\hline 45 & $88,61 \mathrm{bDE}$ & 91,88 aA & $0,22 \mathrm{aBCD}$ & $0,53 \mathrm{bc}$ & $0,08 \mathrm{bD}$ & $0 \mathrm{aA}$ & $2,048 \mathrm{aA}$ & $1,271 \mathrm{aA}$ \\
\hline
\end{tabular}

Em relação à eclodibilidade, observou-se que ovos mantidos nos ninhos automáticos apresentaram maiores eclodibilidades do que os ninhos manuais, com exceção nas aves de 39 semanas, as quais apresentaram ovos com taxas 
ROVARIS, E. et al. Efeito do ninho com coleta manual versus automática na eclosão de ovos incubáveis. PUBVET, Londrina, V. 8, N. 18, Ed. 267, Art. 1779, 2014.

de eclosão semelhantes aos dos ninhos automáticos. Comparando as diferentes semanas em relação a cada ninho, observou-se que os ovos mantidos nos ninhos manuais, oriundos de aves com 38,39 e 40 semanas apresentaram melhores taxas de eclosão, entretanto os ovos de aves com 40 semanas não diferiram das demais semanas. No ninho automático não houve diferença de eclosão entre as idades.

A melhor eclosão dos ovos coletados por ninhos automáticos pode ser explicada conforme citado em Fiuzza et al. (2006) os quais descreveram que em regiões quentes ocorrem mortalidade embrionária inicial, portanto é necessário realizar uma coleta eficiente e rápida. Analisando a mortalidade inicial deste experimento observa-se que esta foi maior nos ovos advindos de ninhos manuais em média $0,71 \%$ superior em relação aos ovos do ninho automático. É importante ressaltar que a coleta mecânica reduz em aproximadamente 60 a $70 \%$ o tempo de coleta em relação ao sistema manual, permitindo desta forma uma coleta mais eficiente (SILVA, 2012). O potencial de eclodibilidade do ovo, logo após a postura, pode, no máximo, ser mantido, mas não melhorado. Se os ovos forem manipulados de forma errada, o índice de eclodibilidade diminui rapidamente.

Analisando a contaminação bacteriana verificou-se que o ninho manual propiciou maiores índices para contaminação por bactérias, com exceção das idades de 38, 39, 44 e 45 semanas. Na idade de 37 semanas não houve diferença significativa entre os dois tipos de ninho. Isto pode ser explicado pela maior agilidade de coleta e desinfecção dos ovos, pois a microbiota bacteriana existente na superfície da casca pode infectar e causar mortalidade de embriões e pintos recém-nascidos. Scott e Swetnam (1993) citado por Cony et al. (2008) explicam que durante o processo de resfriamento dos ovos, há um fluxo natural de ar da superfície para o interior dos ovos que carreia contaminantes por meio dos poros da casca. Dessa forma, os ovos devem sofrer desinfecção o mais rapidamente possível após a postura por métodos e com compostos adequados (MAULDIN, 2002; SESTI, 2005). 
ROVARIS, E. et al. Efeito do ninho com coleta manual versus automática na eclosão de ovos incubáveis. PUBVET, Londrina, V. 8, N. 18, Ed. 267, Art. 1779, 2014.

Com a utilização de ninhos automáticos há uma substancial melhora na qualidade microbiológica pelo menor tempo de exposição dos ovos no ninho, reduzindo a incidência de ovos sujos, trincados e quebrados (SILVA, 2012).

Os dados referentes aos índices de contaminação deste trabalho concordam com Quarles et al. (1970) citado por Cony (2008), os quais compararam os índices de contaminação bacteriana e fúngica no ar, na superfície da casca dos ovos e eclodibilidade dos ovos férteis de aves criadas em aviários com cama de serragem e ninhos com maravalha de madeira comparadas com aves criadas em aviários com piso de arame e ninhos com sistema plástico de retirada de ovos através de rolagem. Os autores observaram que o percentual de eclodibilidade foi significativamente inferior e a contagem bacteriana foi entre 20 a 30 vezes maior na superfície da casca dos ovos das aves criadas no aviário com cama de serragem e ninho de maravalha.

Cabe ressaltar ainda que, o material do ninho manual (maravalha) e a esteira dos ninhos automáticos precisam ser desinfetados, assim também como os tapetes dos ninhos que devem ser limpos com frequência para evitar a contaminação de ovos por bactérias e fungos. Elguera (1999) explica que é impossível produzir um ovo estéril, pois mesmo ovos recolhidos diretamente do oviduto já estão contaminados. Porém a desinfecção de esteiras de ninhos automáticos se faz necessária, além de ser um processo mais fácil do que a desinfecção de ninhos manuais. E isto explica a maior contaminação de ovos com coleta manual.

Sesti (2005) também cita que os ovos sempre terão a presença de microorganismos na casca, podendo contaminar-se antes da ovulação ou durante a formação no trato reprodutivo. Parte dos microorganismos é aderida à casca quando o ovo passa pela cloaca, por onde passam também as excretas (Mauldin, 2002).

Entre as idades no ninho automático as semanas de $38,39,44 \mathrm{e}$ 45 diferiram em relação às outras idades, no manual a idade com maior índice de contaminação foi 40 semanas, porem somente diferiu estatisticamente das 
ROVARIS, E. et al. Efeito do ninho com coleta manual versus automática na eclosão de ovos incubáveis. PUBVET, Londrina, V. 8, N. 18, Ed. 267, Art. 1779, 2014.

idades de 36 e 37 semanas, que foram as idades com menor contaminação. Cabe ressaltar que a contaminação por bactérias ficou acima do padrão da linhagem cobb que é $0,15 \%$ nas idades avaliadas neste estudo.

Não houve contaminação por fungos nos ovos com coleta automática, já nos ovos com coleta manual apenas trêsidades das matrizes ocorreu contaminação (42, 43 e 45), sendo que na 45a semana ocorreu maior contaminação seguido das semanas 43 e 42. Esta contaminação por fungos somente nos ninhos manuais provavelmente ocorreu por este ser forrado com palha de arroz e os fungos crescem e se proliferam bem em cereais, onde geralmente encontram um substrato altamente nutritivo para o seu desenvolvimento (Dilkin 2002). Porém a porcentagem de contaminação ficou abaixo da tabela padrão da linhagem Cobb.

Em relação ao índice de ovos trincados não foi observado diferenças entre ninhos e também entre idades, o que diferiu de Pilottoet al. (2010) que verificaram maior índice de ovos trincados em ninhos adaptados para coleta automática do que em ninhos com coleta manual. Estes autores justificaram o maior número de trincados em ninho mecânico devido a correia de transporte ser estreita, o que difere deste experimento, onde os modelos de ninhos utilizados possuem esteira largas.

Já Worley e Wilson (2000) citados por Silva (2012) descrevem que o ninho mecânico por permitir realizar um maior número de coletas por dia, o que reduz o número de ovos trincados e também melhora a qualidade microbiológica nos ovos.

Os dados de aproveitamento de ovos e ovos postos na cama estão na tabela 2.

$\mathrm{Na}$ avaliação de ovos de cama os ninhos com coleta manual apresentaram melhores resultados, assim também como no aproveitamento de ovos, com exceção das idades de 39,44 e 45 semanas onde os ninhos automáticos propiciaram índices de aproveitamento semelhante aos ninhos manuais. Estes dados foram semelhantes aos encontrados por Pilottoet al. 
ROVARIS, E. et al. Efeito do ninho com coleta manual versus automática na eclosão de ovos incubáveis. PUBVET, Londrina, V. 8, N. 18, Ed. 267, Art. 1779, 2014.

(2010) os quais também encontraram maior porcentagem de ovos de cama em ninhos com coleta automática.

Tabela 2. Porcentagem de ovos incubáveis e ovos de cama nas diferentes idades das matrizes de frango de corte e tipos de ninhos.

\begin{tabular}{|c|c|c|c|c|}
\hline \multirow[b]{2}{*}{ Idade } & \multicolumn{2}{|c|}{ Ovos de cama(\%) } & \multicolumn{2}{|c|}{ Ovos incubáveis(\%) } \\
\hline & Manual & Automático & Manual & Automático \\
\hline 35 & $2,53 \mathrm{aA}$ & $6,82 \mathrm{bB}$ & $96,76 \mathrm{Aa}$ & $95,70 \mathrm{bABC}$ \\
\hline 36 & $2,94 \mathrm{aA}$ & $6,06 \mathrm{bA}$ & 97,09 aA & $94,57 \mathrm{bC}$ \\
\hline 37 & $2,46 \mathrm{aA}$ & $6,14 \mathrm{bA}$ & 96,67 aA & $95,21 \mathrm{bBC}$ \\
\hline 38 & $2,27 \mathrm{aA}$ & $6,22 \mathrm{bA}$ & 97,24 aA & 96,31 bABC \\
\hline 39 & $2,70 \mathrm{aA}$ & $6,22 \mathrm{bA}$ & 96,73 aA & 96,74 aAB \\
\hline 40 & $2,40 \mathrm{aA}$ & $6,25 \mathrm{bA}$ & 97,74 aA & 96,03 bAB \\
\hline 41 & $2,60 \mathrm{aA}$ & $6,46 \mathrm{bA}$ & 97,57 aA & $95,97 \mathrm{bABC}$ \\
\hline 42 & $2,34 \mathrm{aA}$ & $6,09 \mathrm{bA}$ & 97,93 aA & 96,78 bAB \\
\hline 43 & $2,29 \mathrm{aA}$ & $6,22 \mathrm{bA}$ & 97,94 aA & $96,70 \mathrm{bAB}$ \\
\hline 44 & $2,23 \mathrm{aA}$ & $5,99 \mathrm{bA}$ & 97,57 aA & 96,84 aAB \\
\hline 45 & $2,19 \mathrm{aA}$ & $6,04 \mathrm{bA}$ & 97,53 aA & 96,66 aAB \\
\hline
\end{tabular}

Médias seguidas de mesma letra minúscula na linha não diferem estatisticamente pelo teste Fisher e médias seguidas de mesma letra maiúscula na coluna não diferem estatisticamente pelo teste Student Newman Kewls, ao nível de 5\% de probabilidade.

Silva (2012) explica que uma das desvantagens do ninho automático é a propensão a postura de ovos na cama. Entretanto, discordaos dados de aproveitamento de ovos obtidos neste experimento. Este autor descreve que pela coleta mais ágil e menor tempo de permanência no ninho o aproveitamento de ovos é melhor em ninhos automáticos.

Analisando os ovos postos na cama em relação à idade, nos ninhos com coleta manual não foi encontrada diferença, já nos ninhos com coleta automática apenas na idade de 35 semanas houve postura de cama superior às outras idades.

O aproveitamento de ovos foi semelhante em todas as idades nos ninhos manuais enquanto nos ninhos automáticos na idade de 36 semanas houve o pior aproveitamento, entretanto, este não diferiu das idades de 35, 37, 38 e 41 , enquanto que as outras idades foram similares. 
ROVARIS, E. et al. Efeito do ninho com coleta manual versus automática na eclosão de ovos incubáveis. PUBVET, Londrina, V. 8, N. 18, Ed. 267, Art. 1779, 2014.

Outro aspecto importante a ressaltar é a escassez de mão de obra, em granjas que possuem ninhos automáticos, onde obtêm-se uma redução de até $30 \%$ na mão de obra, e esta também influencia nos resultados, como demostraram Borsa e Cruz (2008), avaliando duas granjas produtoras de ovos férteis, em relação à viabilidade, produtividade, incubabilidade e eclodibilidade, onde uma delas possuía funcionários mais especializados e a outra granja com funcionários menos especializados, com este trabalho demonstraram como a mão de obra é essencial, pois a granja com funcionários mais especializados obteve melhores resultados.

\section{Conclusões}

Os resultados mostram que os ovos coletados em ninhos automáticos apresentam melhores resultados de eclodibilidade e menores porcentagens de contaminação bacteriana e fúngica.

Já os ninhos manuais apresentam maiores índices de aproveitamento para incubação e menores índices de ovos de cama.

Não há diferença no número de ovos trincados entre ninhos e idades das matrizes.

\section{Referências Bibliográficas}

BORSA, A. CRUZ, C. A. Interação entre mão de obra e produtividade em matrizes pesadas comerciais. Revista ColloquiumAgrariae, v. 4, n.1, p. 23-29, 2008.

COBB-VANTRES. Guia de manejo da incubação. Guapiaçu - SP, Brasil. 2008.

CONY, H.; VIEIRA,S.;BERRES, J.; GOMES, H.; et al. Técnicas de pulverização e imersão com distintos desinfetantes sobre ovos incubáveis. Ciência Rural, Santa Maria, v.38, n.5, p.1407$1412,2008$.

DILKIN, P. Micotoxicose suína: aspectos preventivos, clínicos e patológicos. Biológico, v. 64, n.2, p. 187-191, São Paulo, 2002.

ELGUERA, A. M. Relação entre o manejo de reprodutoras de carne e a qualidade dos ovos incubáveis. In: II Simpósio técnico sobre matrizes de frango de corte,1999, Chapecó. Resumos... Chapecó: ACAV, 1999. p. 17-27. 
FIUZA, M. A. et al. Efeito das condições ambientais no período entre a postura e o armazenamento de ovos de matrizes pesadas sobre o rendimento de incubação. Arquivo Brasileiro de Medicina Veterinária e Zootecnia, v.58, n.3, p.408-413, 2006.

HOLCMAN, A.; MALOVRH, S.; STUHEC. I. Choice of nest by hens of three lines of broiler breeders. British Poultry Science, v.48, p.284-290, 2007.

MAULDIN, J.M. Maintaining hatching egg quality. In: BELL, D.D. ; WEAVER, W.D. Commercial Chicken Meat and Egg Production. 5th ed. Norwell: KluwerAcademicPublishers, 2002. p.707-725.

PILOTTO, F.; RIBEIRO, L.M.A.; CARGNELUTTI, F.A.; KLEIN, A. V. Efeito da transformação do ninho manual modelo holandês em mecânico na postura de ovos de cama em matrizes de frangos de corte. Revista Bras. de Zootec., v.39, n.10, p.2310-2314, 2010.

ROSA ,P. S. ÁVILA, S. V. Variáveis relacionadas ao rendimento da incubação de ovos em matrizes de frangos de corte. Comunicado Técnico - Embrapa Suínos e Aves, n.246, p.13, Concórdia, 2000.

SESTI, L.A.C. Biosseguridade em granjas de reprodutoras. In: MACARI, M.; MENDES, A.A. Manejo de Matrizes de Corte. Campinas: Facta, 2005. p. 244-317.

SILVA, R.L.P. Ninhos automáticos tecnologia e qualidade na produção de ovos férteis. Disponível em < http://www.nftalliance.com.br/ninhos-automaticos-tecnologia-e-qualidade-naproducao-de-ovos-ferteis/>Acesso em 10 de janeiro de 2013.

UNIVERSIDADE FEDERAL DE VIÇOSA. Sistema para análise estatística e genética - SAEG. Versão 9.1 Viçosa, MG:UFV 2008. Acesso em 10 de janeiro de 2013. 